\title{
Empirical Research on Invalidation Request of Invention Patent Infringement Cases in Shanghai
}

\author{
Xiaojie Jing ${ }^{1, a}$, Xianwei Zhang', b \\ 1South China Sea Institute, Xiamen University, Xiamen, 361005, China; \\ ${ }^{2}$ Intellectual Property Research Institute, Xiamen University, Xiamen, 361005, China. \\ ajingxmu121@163.com, bxanwey@icloud.com
}

\begin{abstract}
This paper reveals the findings of an empirical analysis of the invalidation request brought by invention patent infringement cases in Shanghai. By linking the decisions of patent reexamination board and patent infringement cases to a variety of elements, including patents grant numbers, invalidation requesting time, case concluding time, etc., this paper evaluates patent case decisions rendered by court in Shanghai from 2010 to 2016. The result can shed light on current patent litigation strategy and relating research.
\end{abstract}

Keywords: Empirical Analysis; Invalidation request; Invention patent.

\section{Introduction}

In the patent infringement litigation, the accused infringer hold that the patentee's patent has invalid circumstance, and then puts forward the non-infringement defense, in order to get rid of the infringement liability such as stopping the infringement action and compensating the damage.

Under the current patent law system, the patentee can bring the infringement litigation to the court. If the alleged infringer claims that there is no valid reason for the patent involved, the court shall not judge the validity of the patent. The accused infringer must request the Patent Reexamination Board to declare the patent invalidity, and may appeal to court to suspend the proceedings. The court makes a judgment on the request and decides whether to suspend the proceedings. If the suspension order is issued, the infringement litigation must wait for the administrative reexamination and related administrative proceedings finish. Some scholars believe that limited way to request invalidation against patent is the reason of time-consuming litigation, the alleged infringer can utilize the provision to delay the proceedings [1].

Empirical research will help us to understand the patent law enforcement status from different dimension. This paper links the decisions by patent reexamination board and patent infringement cases to a series of variables, including variables related to the parties, the patents, and the concluding time.

\section{Literature Review}

In recent years, scholars have begun to conduct patent invalidity research from analyzing patent information. Harhoff [2] found patent applied by large enterprises is easy to cause disputes than patent of small businesses and individuals. According to EPO's data, $8 \%$ of patent in large enterprises are requested invalid, and 14\% of them were rejected. Reitzig \& Harhoff [3] analyzed the data of European Patent Office from 1978 to 1996, they found that in the field of bio-pharmaceutical, the frequency of patents invalid activity and the value of is positive correlation, the higher the value, the higher the probability of patent invalidity request occurred. Lemley [4] commented on the US Patent and Trademark Office's patent quality and patent review quality. He pointed out that the control of patent quality is essentially composed of two procedures. One is pre-examination action of the Patent Office, the other is public patent infringement litigation. Lemley further noted that the public can judge the quality of the patent application at a lower cost, especially the non-patented prior art information. Based on this, Lemley argued that it would be more efficient to reduce the cost of patent 
examinations and allow a certain number of questionable patent to be issued, these patent will eventually invalidated by the litigation brought by the public.

In China, patent invalidity related research is mainly focus on qualitative analysis, and less concerned with the empirical study on the operating status of patent invalid system. Compared with qualitative research, empirical research is more clear and intuitive. This paper will take the invalidation request of invention patent during the infringement litigation as the research object.

\section{Research Scope and Data Source}

\subsection{Research Scope}

This paper studies the actual operation status of Shanghai invention patent invalidation request in patent infringement litigation.

Firstly, the utility model patent protects the shape, construction or combination of the patented product, and the invention patent not only protects the product, but also protects the method. Secondly, according to China's patent examination system, only the invention patent application must undergo a substantive review to be authorized. For utility model and design, the preliminary examination does not involve a review of the "patentability" substantive conditions, such as novelty, inventiveness and utility. Therefore, from the perspective of the stability of the legal status of the patent, invention patent is significantly superior to the other two types of patents. In addition, the protection period of invention patents is 20 years, longer than the utility model and design patents with 10 years of protection period. The difference in the strength of patent protection will affect the timing of invalidation of the invention patent, invalid choice of reasons and so on. The number of patent infringement cases in China is too large, hence, this research chooses major city as a sample. Shanghai is as typical as a sample because the level and knowledge of the intellectual property (IP) court is outstanding in China. Based on above considerations, the scope of the study is limited to the invalidation request brought by invention patent infringement cases in Shanghai.

\subsection{Data Source}

This paper collects all the invention patent infringement case documents of Shanghai from 2010 to 2016 in Westlaw China. After preliminary filtering, unrelated documents are ignored, 384 rulings were collected, and formed the basic database for analysis.

The patent invalidation request relates to information at multiple angles. In the case of an invalid request, the Patent Reexamination Board may make a determination about the legal status of the patent. The patent itself contains many characteristics such as the patentee, the technical field, the claims.

Such information can be divided into two categories, one is the legal status of patent information, reflecting the legal status of patents and status changes, such as patent authorization, invalid, expiring information; The other is application information, such as the patentee, IPC classification; Patent legal status information can be a good supplement of patent application information. The combination of these two types of information can fully reflect the actual operation of the patent invalidity system.

The empirical analysis includes two tasks: extracting the key information from the judgment and further analyzing the extracted information. The key information related to the analysis includes: docket number, trial court, patent number, name of patent, decision result, concluding time by patent reexamination board.

\section{Empirical Analysis}

\subsection{The distribution of the case concluding period}

This paper divides the concluding period of the invention patent infringement cases into 5 levels, which are within 3 months, 3 months to 6 months, 6 months to 1 year, 1 year to 2 years and more than 2 Year. As can be seen from the Figure 1, 34\% of the cases are concluded from 3 months to 6 months, and $2 \%$ of the cases are concluded within 3 months. That is to say, about $36 \%$ of the cases may be completed within the 6-month trial period limitation stipulated in the China Civil Procedure Law. 
However, due to the complexity of patent cases and the suspension of invalidity cases, more than $60 \%$ of the cases are exceeding the limitation.

\section{Distribution of Case Concluding Period}

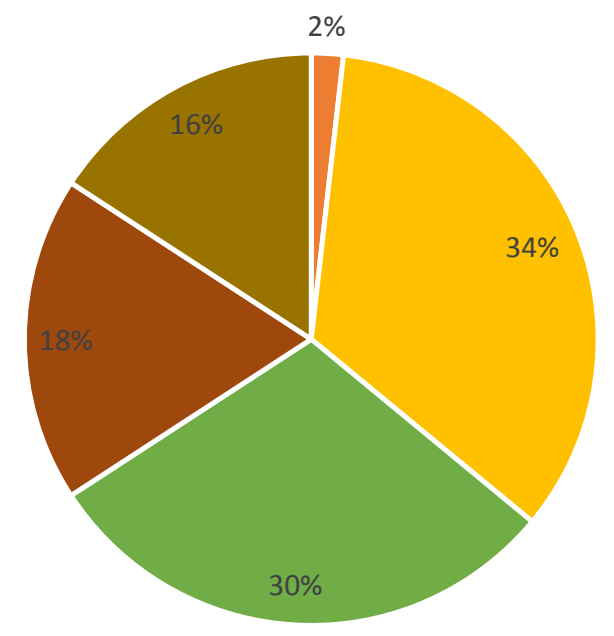

- within 3 months

$\approx 3$ months to 6 months

- 6 months to 1 year

- 1 year to 2 years

- more than 2 years

Fig. 1 Distribution of Case Concluding Period

4.2 The distribution of the invalidation request

\section{Distribution of Invalidation Request}

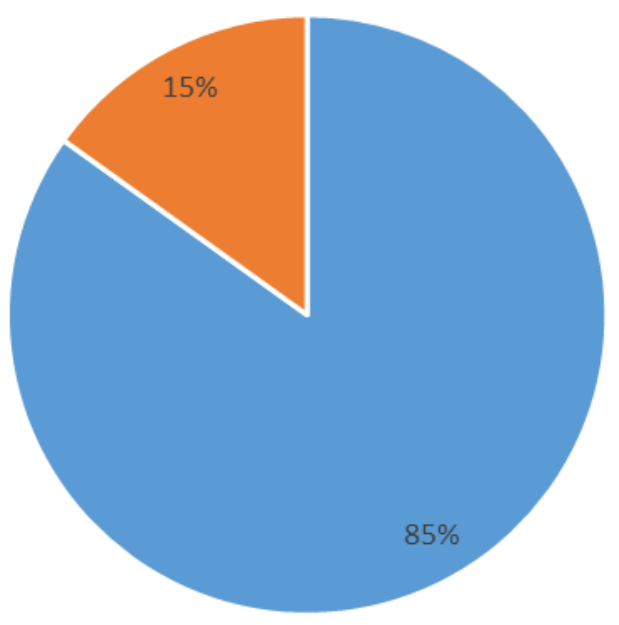

- case non-related to request invalidation

- case related to invalidation request

Fig. 2 Distribution of Invalidation Request 


\section{Distribution of Case Concluding Period of Invalidatation-Realted Case}

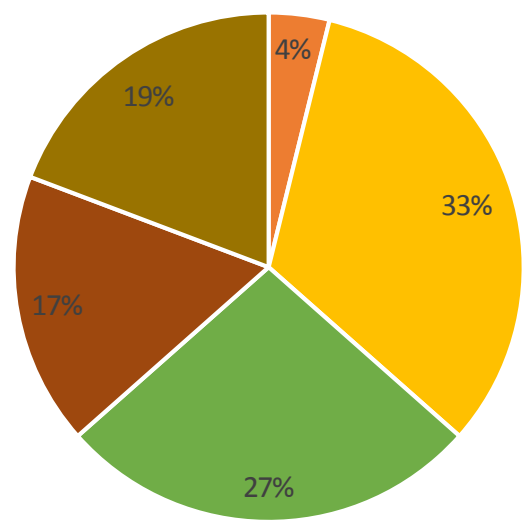

- within 3 months

- 3 months to 6 months

- 6 months to 1 year

- 1 year to 2 years

- more than 2 years

Fig.3 Distribution of Case Concluding Period of Invalidation-Related Case

As can be seen from Figure 2, only $15 \%$ of defendants' request invalidation in the trial. According to Figure 3, 37\% of the invalidation-related cases concluded within the period of 6 months, $64 \%$ of the cases can be concluded within one year. The ratio distribution in Figure 3 is close to the distribution in Figure 1, and it can be assumed that the distribution of the concluding period does not change much even if the case involves invalidation request.

\section{Distribution of Concluding Period of Patent Reexamnination Board}

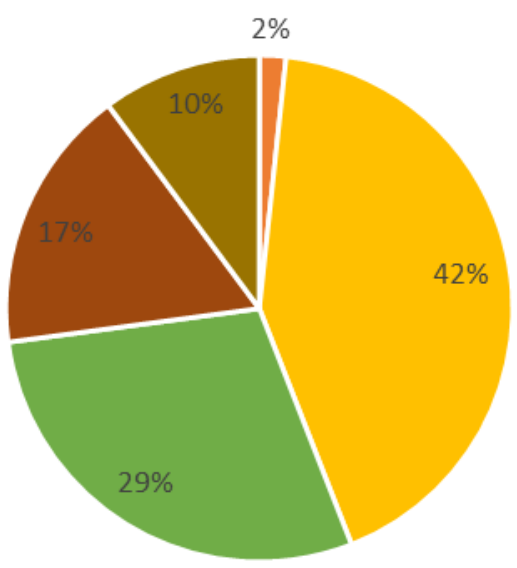

- within 3 months

- 3 months to 6 months

- 6 months to 1 year

- 1 year to 2 years

- more than 2 years

Fig.4 Distribution of Concluding Period of Patent Reexamination Board

As can be seen from Figure 4, the Patent Reexamination Board concluded $44 \%$ of decisions within 6 months, slightly higher than the Court's ratio. $73 \%$ of the review decisions can be made within one year. It is worth noting that the proportion distribution in Fig. 1, Fig. 3 and Fig. 4 is close to each other, and this phenomenon deserves further exploration.

\section{Conclusion}

This paper combines the review decision of the Patent Reexamination Board with the judgment of the court. From the multiple dimensions of empirical research, the following conclusions are drawn. 
a) $36 \%$ of the invention patent infringement cases can be concluded within 6 months; $66 \%$ of the invention patent infringement cases can be concluded within 1 year.

b) Only $15 \%$ of the alleged infringers will plead for invalidation in the case. Why accused infringer must take the invalidation strategy, the reason is worthy of further exploration.

c) In cases involving invalidation request, $37 \%$ of cases can be concluded within 6 months, $64 \%$ of cases can be concluded within 1 year. On the existing statistical results, patent invalidation request does not significantly extend the duration of the trial.

d) The review efficiency of the Patent Reexamination Board is slightly higher than the court, and the distribution of the examination period is very close to the distribution of the concluding period of the court, which needs further study and exploration.

With respect to available data, the next step is to examine the distribution of patent invalidity in different technical areas and to explore whether there are significant differences. This exploration can be combined with the decision of the Patent Reexamination Board to reflect the stability of the patent in the relevant field. Patent in different technology areas may lead to different ligation strategies.

\section{References}

[1] Zhang Peng. Drawback and correction in China's dual-System of patent invalidation judgement. Politics and Law. (2014) No.12, p.126-135.

[2] Harhoff, Dietmar, Frederic M. Scherer, and Katrin Vopel. "Citations, family size, opposition and the value of patent rights." Research policy.Vol.32. (2003) No.8, p. 1343-1363.

[3] Harhoff, Dietmar, and Markus Reitzig. "Determinants of opposition against EPO patent grants - the case of biotechnology and pharmaceuticals." International Journal of Industrial Organization. Vol.22. (2004) No.4, p.443-480.

[4] Lemley, Mark A. "Rational ignorance at the patent office." Northwestern University Law Review. Vol.95.2001 No.4, p.1495-1661. 